\title{
POWER OF SOLID MUNICIPAL WASTE
}

\author{
Valeriy Mykhaylenko ${ }^{1}$ * \\ Gintaras Denafas ${ }^{2}$ \\ ${ }^{1}$ Taras Shevchenko National University of Kyiv, Ukraine \\ ${ }^{2}$ Kaunas University of Technology, Lithuania \\ *Corresponding author: v.mykhaylenko@gmail.com
}

\begin{abstract}
Land pollution belongs to the most serious environmental problems in Ukraine. The existing system of placing municipal solid waste (MSW) on landfills without proper pre-treatment based on ideas of the 1970s still dominates. Natural landscapes of Ukraine are largely destroyed due to legal and illegal landfills that exceed the space of all National parks and natural reserves. Currently Ukraine is going through massive social and political changes that allow modernization of the country on the basis of the fundamental trends of the sustainable development (SD). Waste management is a subject of particular attention. There is risk to give preference to outwardly attractive economic development, without regard to the unified, holistic models of the SD concept.

Landscape ecology is one of the sciences that explore complex issues of interaction between society, economy and environment. It has to be effective in producing appropriate knowledge for landscape-development processes and would be suitable for use in collaborative decisionmaking on a local level.

The purpose of this publication is to highlight opportunities for applied research in the area of MSW management which is the most problematic area in social and environmental measures. This is a subject for international environmental cooperation aimed at ensuring proper quality of Ukrainian landscapes as the country is seeking to be part of Western Europe. This paper presents local feasibility plan aimed at resolving problem of handling municipal waste flows and improving quality of urban landscapes. It is also aimed to show how significant the role of university has been in supporting the Triple Helix model, a driving force of MSW management on the local level.
\end{abstract}

\section{KEYWORDS}

Municipal solid waste, MSW management, landfill, landscape, enhance landfill mining, recycling, sustainable development, Triple Helix cooperation, Baltic countries, university 


\section{INTRODUCTION}

Ukraine is the second-largest country in Europe that occupies 5,7 \% of European land and is sixth by population. Having gained independence in 1991, it declared political willingness to become the EU member country. This will need to address and resolve enormous political, environmental and economic problems. Among other, there are several concerns that trickle down to municipal solid waste management (MSWM). The existing practices in MSWM do not ensure protection of the population and the natural environment from the hazardous effects of poorly managed dumping sites. About one thousand landfills do not meet environmental requirements; the vast majority of them are overloaded. The Ministry of Regional Development Constructions and Housing of Ukraine (Minregion) reported [1] about 6,7 thousand legal and 32 thousand illegal dumping places that cower around 10000 ha and are causing a "creeping disaster".

Environmental Law of Ukraine started taking shape only after Ukraine gained its independence in1991. Prior to 1998, Ukrainian legislation in the field of waste management was fragmented. The Law "On Wastes" adopted in 1998 has become the guideline for a general practice of legal regulations in the field of waste management. This law discloses the basic principles of state policy on waste management and defines authority of all government structures, local government and business entities in the treatment of all waste types in Ukraine.

Social impact of damaged land is still not being taken into account by decision-makers. Ukraine, together with most of the European Countries has already signed the European Landscape Convention (ELC). This document could ensure that citizens have a say on landscape management, planning and protection. Unfortunately the Ukrainian Law "On landscapes" still did not come in force thus an opportunity to implement this effective instrument remains unrealized. Human protests against improper MSWM are getting more sound in several regions. This situation is true for almost all residential areas in Ukraine [2, 3]. Lack of National waste treatment strategy, insufficient financing of Local Governments (LG) and high risks for private assets involvement are the main concerns of the Ministry's experts. Minregion stressed that the problem is mainly connected with an out-of-date methodology of deposing waste on landfills without any preliminary processing.

There is, however, a potential way to convert MSWM in Ukraine from a "creeping disaster" to a powerful energy source. Waste management has undergone significant paradigm shifts in prominent European countries. Landfill disposal of MSW was the most commonly method worldwide since 1960's. Starting from 1980s, all landfills had to comply with several newly introduced regulations. The next step consisted of combining landfill practices with a Waste to Energy (WtE) and later to Waste to Resources (WtR) approaches. A major drawback of closed landfills is that their aftercare period is limited, and landfills also occupy enormous amounts of land.

Over the past five years, Verkhovna Rada (Parliament) of Ukraine has reviewed close to one thousand programs and 200 development concepts. Each of these programs involves development of corresponding programs on the regional level.

During the period from 1998 to 2004, a strong legal framework was drafted to bring the provisions of this law into effect. To date, more than 50 regulations have been adopted on state level (14 Laws of Ukraine and about 30 governmental decisions and orders), to gradually meet the requirements of European legislation. 
In general, the estimation of the key issues in the field of Environmental Protection in 2012 showed only $5 \%$ of stakeholders' interest to resolve waste management problems in Ukraine, Diagram 1.

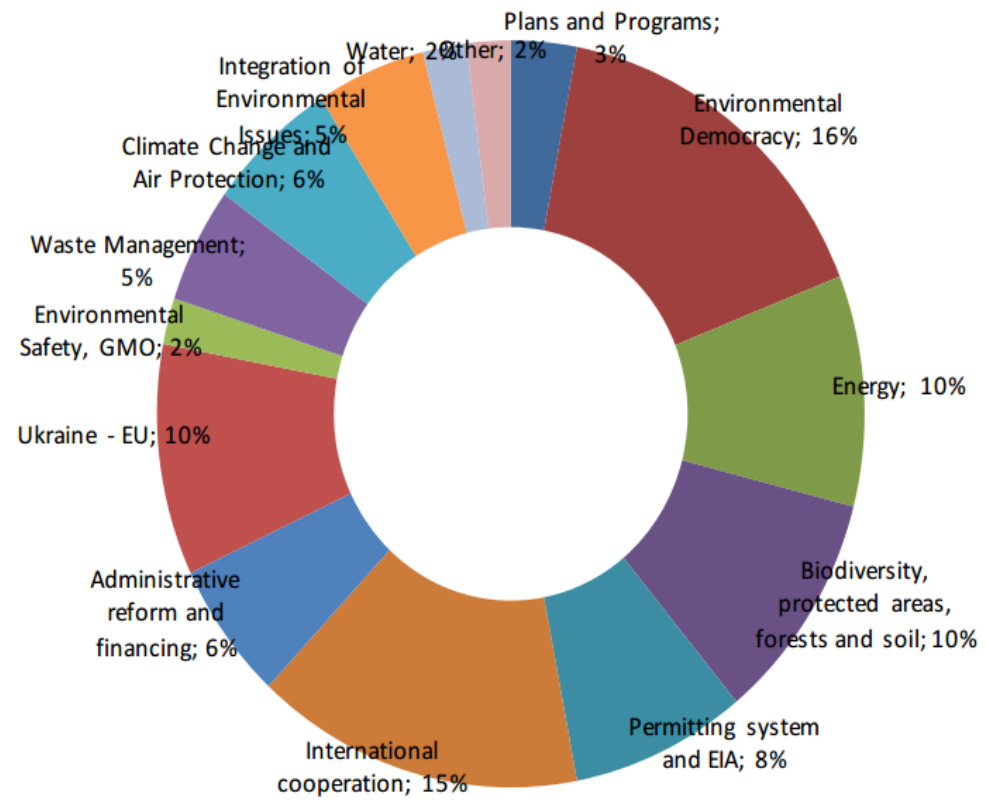

Diagram 1. Key issues in the field of environmental protection, 2012 [5].

Ukraine is going through a massive social and political change that may open way for the modernization of the country on the basis of the fundamental trends of the sustainable development (SD) concept. For country that is searching its own way, it is very important not to make fundamental mistakes. Ukraine is facing the risk giving preference to outwardly attractive economic development, without regard to the unified, holistic models of ecological and social spheres [4]. In order to achieve consensus, Ukraine must go through the implementation of the main provisions of the concept of the SD.

Deloite Experts indicated the most promising areas for development and investment within the MSW industry in Ukraine [5]. Here are some of recommendations:

- Implementation of educational projects and other measures for shaping public culture of separate waste collection;

- Introduction of separate solid waste collection;

- Construction or modernization of plants for processing secondary raw materials and/or usage of secondary Solid Recovered Fuels (SRF).

This is actually how the rest of civilized world is doing it.

\subsection{Sustainability as a Triple Helix approach}

Authors [7] are considering landscape performance in the context of SD, based on a comprehensive consideration of environmental, social and economic functions and without compromising the potential to deliver goods and services to future generations. In sustainable landscape development, humans change the landscape to improve its functioning and create 
additional value. Therefore, scientific knowledge should allow linking of the physical structure and functioning of the landscape to the economic, sociocultural, and environmental values demanded by its users [8].

The concept of the Triple Helix of university-industry-government relationships initiated in the 1990s by Etzkowitz [9,10]. Ranga and Etzkowitz [11] introduced the concept of Triple Helix systems as an analytical construct that systematizes the key features of university-industrygovernment interactions into an 'innovation system' format. Triple Helix has been widely discussed in academic circles in the "innovation system" [12]. The authors introduce the concept of triple systems, which make it possible to define new ways of appearing through a creative combination of separate structures and provide new understanding of the dynamics of innovation.

This format is very new to Ukraine. The aim of this paper is to present a feasibility study introduced to Science Park of Taras Shevchenko National University of Kyiv (KNU) in order to start and to support the Triple Helix dynamics in MCWM as a set of components, relationships and functions among scientific institutions, industry, communities and LG.

Ukrainian reality demonstrates a willingness to operate in a proper way to become a part of EU. In many cases this will require changes in the way government institutions currently operate [13] and will necessitate recognition of the importance of effective MSWM for municipal and federal SD. In view of this, the feasibility study described at paragraph 3.3. may respond to the question whether or not adequate financing, a supporting institutional and policy environment are available to meet the goal.

\section{KEY STAKEHOLDERS}

\subsection{Government}

Politics inevitably play a large role in MSW systems. Structure, operation, and governance of MSW systems are affected by the relationship between State and LGs, the role of party politics in LG, and the extent that citizens participate democratically in policy making processes.

Government of Ukraine has passed amendments to its municipal waste law that introduced among other changes a separate municipal waste collection system. Legislative initiatives planned expansion of local communities' rights regarding the ownership of waste and obliging citizens to separate collection of waste. All co-ordination should be done by the Ministry of Environmental Protection of Ukraine. The key State governmental institutions and their branches that are responsible for proper MSWM are listed below:

\section{Ministry of Environment and Natural Resources \\ - State Environmental Inspectorate \\ - State Agency for Environmental Investments \\ Ministry of Regional Development Constructions and Housing \\ - State Architectural and Constructions Inspectorate \\ State Agency for Investment and National Projects of Ukraine \\ - 'Clean City' Project under auspices of (former) President of Ukraine \\ Ministry of Health Care \\ - State Sanitary and Epidemiological Services}

In spite of number state institutions that are partially or totally responsible for proper MSWM operations, the situation with the protection of landscapes has significantly worsened. There is 
no sufficient communications between State and local government officials, local communities and businesses that operates in the MSW sector. Community organizations state in their reports that specialized Ministries of Ukraine turned to political institutions which lack the necessary power and influence to prevent trade distortions in the formation and execution of Government policy. It mainly concerns the Ministry of Environment and Natural Resources of Ukraine, which has existed for 22 years and is constantly under the process of reform. From our view, State officials do not worry much about waste management problem as they claim it to be LG responsibility.

Prominent LG officials joined Association of Ukrainian Cities (AUC) and Association of Small Towns of Ukraine (ASTU). The main AUC's activities are aimed at the development of the Ukrainian communities and strengthening local government. Within the household and commercial services AUC is expanding its activities to collection and utilization of domestic waste [13]. Nevertheless, each change at the State Government policy level generates more than $50 \%$ of new LG authorities that are too detached from MSWM issues.

\subsection{Businesses and donors}

Low levels of innovation and investment activity from business entities in the field of MSWM can explain slow rate of implementation of modern technologies for separate collection, sorting, and energy recovery from solid household waste. To address this challenge "The Clean City" National project [14] was initiated under the auspices of former President Yanukovych. It was designed to attract investment the development of new waste processing technologies in Ukraine. The project did not achieve the goal due to poor project management. Moreover, its activities sometimes went in contradiction to the Minregion policy.

Among the most successfully operating companies are the following:

Remondis - provides services to the public, municipalities and businesses on the effective use of recyclables. They perform waste collection, disposal and recycling, water supply and wastewater treatment, develop innovative recycled products and produce different forms of alternative energy.

Veolia - a subsidiary enterprise of VEOLIA ES Ukraine. The company participates in the organization and maintenance of the "Separate collection" program. This program is directed at the separation and saving of the essential contained components from solid municipal waste that is aimed for recycling.

Kramar Recycling is a company with years of experience in the field of integrated waste management. Kramar Recycling provided a long-standing good reputation, and high quality products.

Waste Management Systems is one of the entities that provide services for MSW collection, removal, disposal and recycling household waste that operates in Ukraine since 2011. It holds a strong position in the Ukrainian market in the treatment of various types of waste.

Granic LTD provides service of garbage collection in Zaporizhzhya from 1998 onwards, is implementing separate waste collection and participate in "Zero Waste" City project.

There are several international donor projects successfully operated at the local level. The most visible are:

DESPRO Project “Decentralization Support in Ukraine”, funded by Switzerland government, implemented a step-wise planning process in the field of MSW Management in Vinnytska oblast.

The UNDP project is being operating since 2004 on building the capacity of local communities to participate in decision-making process and work together to strengthen the local socio-economic and environmental governance to achieve SD. 
"Waste Governance ENPI -East" is operating in Zakarpattya oblast aimed at promoting of a sustainable MSW collection and sorting operations, promoting application of recycling systems and safe disposal of waste.

The Public-Private Partnership Development Program (P3DP), funded by the USAID, operates since October 2010, cooperating closely with the AUC and 'Clean City' project aimed at improving MSWM facilities.

Dialogue, the USAID funded project, focused on enhancing of the AUC capacity building and training programs for LG officials and local consultancies.

\subsection{Public Sector}

In last three decades a strong correlation of education and socio -economic development observed. Ukrainian volunteers' and non-governmental organisations (NGOs) make a considerable input to educate public, raising awareness on MSWM problems, introducing 3R's rule, conducing cleaning actions, seeks to make Ukrainian legislative processes democratic and transparent. There is a wide network of NGOs that provide assistance in the protection of environmental rights, environmental education, science and culture. Among successfully operating are: Resource and Analysis Centre (RAC) "Society and Environment", BEI (Bureau of Environmental Investigations), EPL (Environment, People, Law), "MAMA-86", Green Wave, Environmental (Green) Investment Fund, IBCentre, "Let's do it, Ukraine!" and many other.

It should be noted, the NGOs activities in the field of MSWM and public outreach is often more expressive and productive due to their international contacts and numerous educational donor programs.

\section{ROLE OF UNIVERSITIES}

Universities are perceived by society as centres of production of ideas, knowledge and practical skills with a high level of public trust; provide state workforce and technological innovation. Nevertheless, the title role in MSW study among the scientific institutions belongs to State Institution "Institute of Environmental Economics and Sustainable Development of the National Academy of Sciences of Ukraine" and The Scientific Engineering Centre "Biomass", LTD. To this list can also be attributed Ivan Franko National University of Lviv, National University of Kyiv-Mohyla Academy and Chernivtsi National University. Unfortunately, the leading role of KNU and other universities is not that much considerable. In spite of seeing Universities are as centres of knowledge transfer to future generations, they are in Ukraine not respond to the nowadays MSWM global challenges and operate mainly in a "classic" way. They still not realise their unique potential abilities to operate as the "global laboratory" providing correlation of nature, human beings and society through the learning process in the sphere of environmental management, and preserving landscape quality.

There are certain things needs to discuss urgently for finding a way to be transformed into unique institutions that offer holistic approach in MSWM to scientific communities, students and alumnus. This is what the Department of Geography of KNU learned having been involved into the SWC-ENV-IND international project supported by Swiss National Scientific Fund [15]. This study provided results from MSW composition research campaigns conducted during the period of 2009-2011 in four regions of Eastern European countries, namely Lithuania, Ukraine, Georgia and Russia.

Within the project outcomes there were unpredicted positive finding as implementing of international scientific conferences in Kyiv (Ukraine), Kutaisi (Georgia) and SPB (Russia). The conference networking Universities were: Kaunas University of Technology (Lithuania), 
Paul Scherrer Institute (Switzerland), Akakiy Tsereteli State University (Georgia) and SaintPetersburg State Polytechnic University (Russia). The conference entitled "Sustainable Municipal Solid Waste Management in Eastern Europe: Prospects for the Future" took place at KNU in 2011. The most valuable input provided universities of Sweden: The School of Natural Sciences, Linnaeus University, Finland: Lappeenranta University of Technology and Zakarpattya branch of Kyiv Slavic University, Ukraine. This event was a nice opportunity to introduce the Landfill Mining concept to Ukrainian officials and scientists [16]. Two years later the next KNU conference entitled "Interdisciplinary dimensions of landscape research" extended the successful international cooperation [17].

\subsection{MSW morphological content}

Landfills that were not closed appropriately are of primary importance as the EU legislation demands closure of non- compliant landfills, re-cultivation followed by soil and groundwater remediation. Over recent times, the MSW morphologic composition in Ukraine has changed, but the number of scientific papers on this study is very limited. While earlier food waste was the predominant component in the composition, at present there are about $50 \%$ of municipal wastes composed of used packaging, primarily polymeric and combination, with the majority of their types being resistant to biological degradation and able to remain in the ground for many years.

The MSW fractional composition study realized within the SWC-ENV-IND project [15] under the leading role of KNU experts. The project outcomes demonstrated that the quality of the recyclable and residual MSW is strongly influenced by the seasonal variation in MSW composition. The results indicated high content of recyclable resources in the raw material and may clearly demonstrate the economic attractiveness of solid waste as an energy source. The market opportunities of potential recyclables throughout Ukraine were roughly estimated as $\$ 5$ billion. The caloricity values of MSW samples assessed as 7 - $8 \mathrm{MJ} / \mathrm{kg}$ that may be considered and used as a low-calorie raw material. The biological carbon rate was estimated as $12.7 \%$ of the combustible waste, which permitted calculate the greenhouse gas emissions from landfills, also a valuable raw material for energy recovery [18].

\subsection{Enhanced landfill mining}

Planned actions to reduce and prevent impacts to the environment and get extracted valuables from dump sites are proposed in a new approach known as "landfill mining”. Landfill mining (LFM) was defined by Krook et al. [19] as "a process for extracting materials or other solid natural resources from waste materials that previously have been disposed of by burying them in the ground". LFM has been touted as a way to recover valuable materials discarded over the years. The rise of raw material and energy costs promotes the process of LFM to be economically feasible, but this approach must be adjusted in regulations [16, 20-22].

It is evident that waste management has become a multi sectorial, international problem and new methods are required to reduce greenhouse gas emissions, landfill leachate and land shortage elsewhere in the world. There are also several environmental threats complementing waste disposal and treatment operations. Action on climate change has already led the way in helping to decouple growth from the use of carbon. Synergy of landscape convention, transboundary pollutions, waste transportation and land use issues are evident.

Krook, Baas [22], Bosmans et al. [23] introduced a new, more stringent definition of urban mining. Apart from old landfills, enhanced landfill mining (ELFM) is also applicable to new landfills by considering them as temporary storages. In that approach landfills become future mines for materials which could not be recycled with existing technologies or show a clear potential to be recycled in a more effective way in near future [21-25]. The feasibility of 
ELFM is studied by synthesizing the research on the Closing the Circle project, the first ELFM project targeting the 18 million metric ton landfill in Houthalen-Helchteren in the East of Belgium [21].

\subsection{Feasibility study}

The Triple Helix thesis states that the university can play an enhanced role in innovation in increasingly knowledge-based society [26]. Within the SD concept the driving role of science lays in the collaborations between producers, users and decision-makers. In various countries, the Triple Helix concept has also been used as an operational strategy for regional development and to further the knowledge-based economy. The question remain whether or not it is possible to build interaction between the principal actors of the landscape polluters, businesses and local government in Ukraine to attract investors for introducing environmentally sound services. To respond to this question a feasibility study that combined scientific, technical and human resources proposed under the newly established Corporation 'Scientific Park of KNU”. Its mission includes advancement and commercialization of smart research and development projects in the field of theoretical and applied sciences. Among its goals is organization of conferences and meetings aimed at building a bridge between scientific, educational and industrial modules in Ukraine.

The "Alternative: Power of municipal solid waste" project was submitted to Scientific Park of KNU. The project aimed at improving the investment climate to make vital energy saving technologies for MSWM and implementing geo-ecology principles to reduce the anthropogenic impact on the landscapes around small cities. There is a plan to create the conditions for study a full cycle of MSW streams "from the cradle - to the grave" and introduce effective energy-saving technologies in industry. University campus together with the landfill located in Kyiv suburb will serve as a demo in WtE and WtR research. The KNU students' campus of 10 thousand people (Fig.1) and the MSW cleaning company that is going to provide landfill for services will act as a single platform for geo-ecological and social research aimed at minimizing the MSW flow at their formation, monitoring impact of polluted area on environmental quality and attract business for investments.

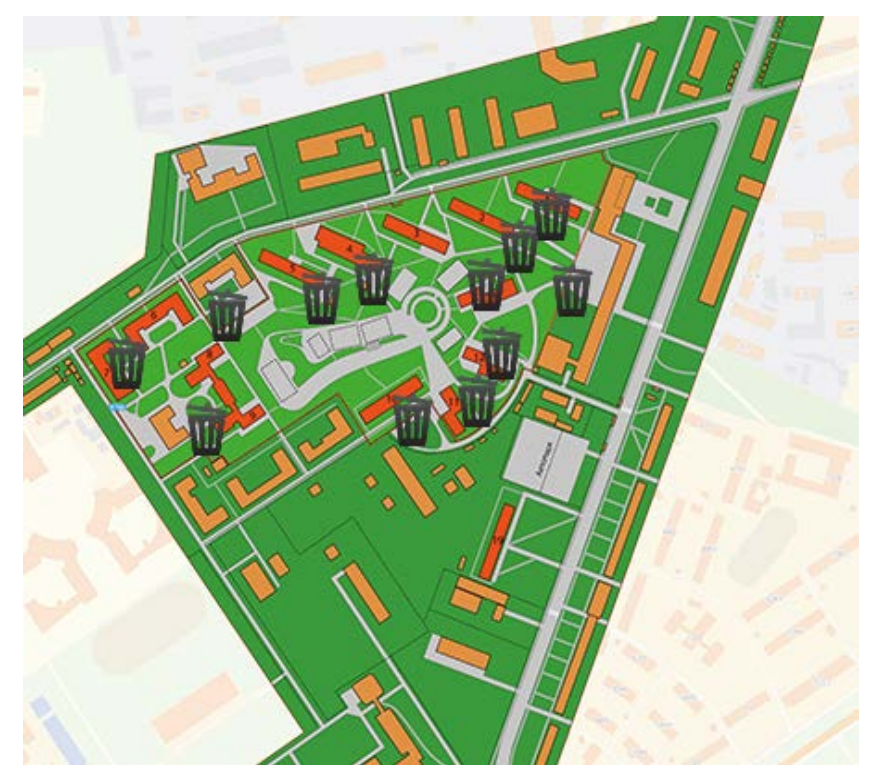

Figure 1. Students' campus view plan with suggested placements of MSW containers [27]. 
There will be two different waste resources involved in the study: fresh waste from the campus area, and also previously disposed waste at the landfill. The waste from the campus is planning to separate for three, up to six fractions in situ.

" Zero waste” technology will be applied to collected fractions at the landfill. A pilot plant for obtaining Solid Recovered Fuels (SRF) is going to be established. Engineering and manufacturing alternative fuel components will provide technologies to obtain energy from indivisible MSW residue, certification of final products and providing recommendations to energy-intensive and heat-generating utilities. This source of energy is to large extent ignored in Ukraine, but can increase energy-independence of Ukraine. For example, cement industry in Estonia obtaining benefits in getting 30\% of energy using SRF as alternative energy sources. Actually, in Europe waste fuel in cement industry is recognised as best available technology. Ukrainian cement industry may be classified as using best available technology so fare may bring important message in the just started EU-cohesion.

Seasonal variations in energy content will be studied in more effective way due to innovative MolokDomino deep collection containers (Photo 1,2). This type of permanent storages of waste does not permit illegal mining of valuable components, which is popular in Ukraine. Relevance of the project in Ukraine stems from the need to adapt EU Directive that categorically prohibit disposal of solid waste to landfills. This issue has economic, social, organizational and even political aspects that should be solved in a comprehensive manner.

As a result, the project is expected to create a model unit of researchers and businesses to perform long-term scientific study and monitoring geo-ecological, engineering and social technologies, introducing ELFM on the Scientific Park platform. It foresees introducing of know-how pilot technology for producing the alternative fuel on the WtE principle.
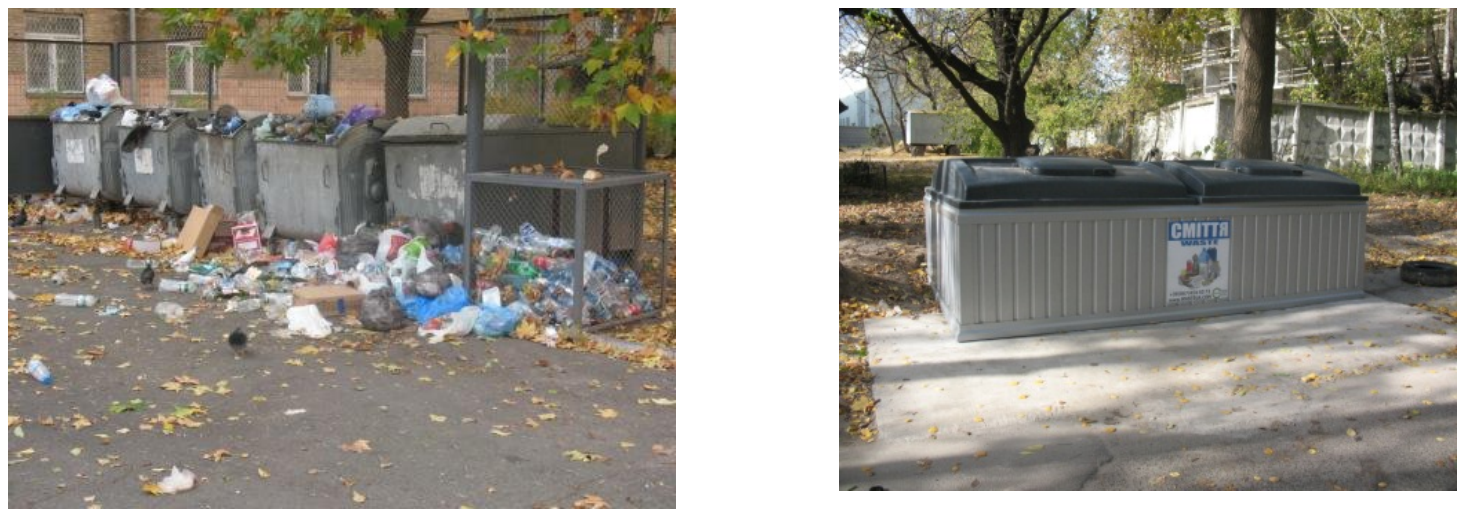

Photo 1, 2. MolokDomino deep collection containers (right) will replace the existing ones.

There are various grades of waste fuel exist, ranging from untreated, mixed loose waste (fit to mass burn facilities only) to specially treated pellets fuels. The study aims at achieving quality standards for SRF, according to CEN/ TC 343 [28]. It is anticipated that solid fuel prepared from non- hazardous waste will be utilised at cement plants as alternative fuel. Also it is 
possible to propose SFR for energy recovery in incineration and co-incineration plants and meeting the classification and specification requirements laid down in EN15359 [29, 30].

Pelletizing simplifies storing and transportation of waste fuels, therefore their technical and economic and aspects should be studied. The mobile experimental unit will be available for this first drawing plan. The method of MSW processing will be chosen based upon local conditions:

- MSW composition and its climatic conditions and seasonal changes;

- annual volumes of solid household waste generation;

- a demand for power resources at the market and recyclable materials;

- Marketing of SRF use abilities and economic factors.

Economic effect will depend on resources allocated to attract energy-saving technologies in industry.

The project also foresees strengthening professional training of university graduates. Professional training will provide a long term prospect to preserve the quality of landscapes in accordance with the ELC and CCC. It also assumed the improvement of education curricula and training of university students, increasing collaboration with the University of Western Europe that promote formation of innovation climate to national economy. New curricula for academic disciplines will be developed and introduced to students. Scientific workshop will be organized by KNU in collaboration with Kaunas University of Technology (Lithuania) and Linnaeus University (Sweden). Scientific Conference on MSWM will be scheduled to take part together with universities of the Baltic countries and Georgia. Public awareness campaign for local authorities conducted, outreach for students and campus staff introduced and public opinion polls collected.

The project relies on support of socially responsible business such as cement and building construction, metallurgy and energy-generating companies in housing sector for getting power to conduct research on usage MSW as secondary energy resources. The social component is aimed at efficient exploration of secondary resources and preserving quality of urban landscapes. It also foresees implementation of MSWM at local level to enhance landscape quality management on SD principles. WtE will reduce environmental risks from landfills. The results can be used all over Ukraine and partner countries.

\subsubsection{Activities and implementation time-line}

To meet the project goals, open dialogue among the stakeholders will be introduced and joint action plan for the period of project activities will be developed and approved. The positive effect is anticipated due to establishing an appropriate conscious and human behaviour of students' community, introduction of environmentally-sound waste separate technologies and innovating methods for manufacturing alternative fuels. A Triple Helix model will support to meet the following urgent tasks:

- Launching of separate MSW collection at students' campus of KNU of Kiev;

- Setting up a pilot plant to study technological features of manufacturing the alternative fuels at the landfill;

- Establishing of research laboratories for certification of alternative fuels;

- Review of market for SRF in Ukraine;

- Elaborating ELFM Guidelines Manual and issuing a practical guide on MSWM upon requests of local authorities. 
Long-term goals will respond to introducing of principles of MSWM to preserve the quality of urban landscapes and enhancing cooperation with partner universities, landfill remediation and transfers of technologies. Dissemination of MSWM best practices is foreseeing by introducing new educational disciplines at KNU and through the Scientific Park web page.

The project activities are planning to be implemented within two phases. In time of pre-design an open discussion of the project proposal will take place at Scientific Park units, between partner organizations, local governments, scientific communities and MSW service providers. Strategic action plan, Project Management Group (PMG) will be identified and research areas defined. PMG takes care of administrative and financial management. The working groups will be focused on technological and economic policy (WG-1), scientific and educational issues (WG-2), and WG-3 unit will act as PR and information facility. 38 units of MOLOK containers will be installed for MSW accumulation. The Scientific Park will establish scientific and engineering research centre for enhanced studies. A pilot Mini-plant with productivity of one ton pellets per hour will be established at the landfill. The quality control laboratory for testing sample fuel will be supplied with devices for determination of humidity, caloric values and heavy metals content.

The second phase foresees a separate MSW collection of toxic and electronic waste. Estimation of economic efficiency of MSW separate collection will be introduced and processing of pellets at pilot plant fixed. The research centre and laboratory will prepare documentation for accreditation and certification of laboratory. Certificate for laboratory operations will be obtained and fuel testing services available for outside organizations. International cooperation in reclamation and closure of landfill extends. Educational courses for environmental managers introduced in collaboration with partner universities introduced. Scientific Conference in conjunction with the universities of the Baltic countries and Georgia for sharing the project outcomes will take place. Final project reports and best practices published on the Scientific Park website.

\section{CONCLUSIONS}

The unresolved problems with MSW landfilling are catastrophic in Ukraine. The stable development of MSWM limited by lack of economic incentives for the development of environmentally friendly technologies, lack of LG experience, as well as the lowest ecological culture among the population. MSWM in Ukraine now is in the process of shifting to the standards expected in developed countries. Legislation of Ukraine actively incorporated the EU experience and is going to prohibit the MSW deposit without a preliminary processing.

Universities should take a leading role in shifting outdated socio-economic model to SD background by means of multidisciplinary scientific approaches. Triple helix cooperation that foresees interaction between university, businesses and government has a greater chance of developing innovations used by all sectorial stakeholders. In this context, the task of Ukrainian scientific community is effectively promoting the best MSWM practices, addressing the SD principles to the conscious part of the society. At this stage landscape ecology may provide conceptual scientific basis for preservation of the unique landscapes of Ukraine by enlarging educational activities and Triple Helix cooperation.

\section{REFERENCES}

[1] State of waste treatment in Ukraine in 2012. 2013. Minregion of Ukraine, National Report. 
[2] Solid Waste Management in Ukrainian Cities, the Role of Urban Population in the Separate Collection of Waste, and Recommendations for Bodies of Local Self-Governance. 2011. UNDP/MGSDP. 1-51.

[3] Municipal Solid Waste Management: Opportunities for Ukraine. Summary of key findings. 2012. IFC, World Bank Group Report. 1-24.

[4] Mykhaylenko V. 2013. Ландшафтна політика в контексті міжнародної екологічної співпраці та сталого розвитку України (Landscape policy in the context of international environmental cooperation and sustainable development of Ukraine). Фізична географія та геоморфологія. 3(71), 197-204 (in Ukrainian)

[5] Kozak Z. Key issues in the field of environmental protection, 2012. 2013. The Year in Review-2012 Environmental Policy and Law. RAC “Society and Environment”. 3.

[6] Solid waste management in Ukraine 2012. Deloitte Report. PJSC “Deloitte \& Touche USC" 1-16.

[7] Termorshuizen J. W., Opdam P. 2009. Landscape services as a bridge between landscape ecology and sustainable development. Landscape Ecol. 24, 1037-1052.

[8] Haines-Young R. 2000. Sustainable development and sustainable landscapes: defining a new paradigm for landscape ecology. Fennia 178. 7-14

[9] Etzkowitz, H. 1993. Technology Transfer: The Second Academic Revolution. Technology Access Report.

[10] Etzkowitz, H., \& Leydesdorff, L. 1995. The Triple Helix - University-IndustryGovernment Relations: A Laboratory for Knowledge-Based Economic Development. EASST Review. 14, 14-19.

[11] Ranga M., Etzkowitz H. 2013. Triple Helix Systems: An Analytical Framework for Innovation Policy and Practice in the Knowledge Society, Industry and Higher Education 27 (4), 237-262.

[12] Rosenlund , J. Hogland W. 2012. Environmental practice and social scientific research in a Triple Helix platform. In: Proceedings of Linnaeus EcoTech- 2012. November 26-28, 2012, Kalmar, Sweden, pp. 8-14

[13] Zarembo K. 2010. Ukraine and the Environment: Together in Noah's Arc. A New Foreign Policy for Ukraine: Expert perspectives, International Centre for Policy Studies. Institute of World Policy, 137-47.

[14] The Clean City National project. At: http://www.ukrproject.gov.ua/en/news/

[15] Seasonality of Municipal Waste Generation and Composition and Corresponding Fluctuations of Various Environmental Indicators for Waste Management and Treatment Facilities (SWC-Env-Ind), 2013. SNSF. In: http://p3.snf.ch/Project-128178

[16] Hogland W., Hogland M., Marques M. 2011. Material Recovery, Energy Utilization and Economics of Landfill Mining in the EU (Directive) Perspective. In: Proceedings of "Sustainable Solid Waste Management In Eastern Europe - Prospects For The Future “, May 19-21, 2011, Kyiv, Ukraine 
[17] Mykhaylenko V., 2013. Landscape policy in the context of international environmental cooperation and sustainable development of Ukraine. Фізична географія та геоморфологія. 3 (71), 197-204 (in Ukrainian)

[18] Denafas G., Ruzgas T., Martuzevičius D., et al., 2014. Seasonal variation of municipal solid waste generation and composition in four East European cities. Resources, Conservation and Recycling. 89, 22-30.

[19] Krook, J., Svensson, N., Eklund, M., 2012. Landfll mining: a critical review of two decades of research. Waste Management .32, 513-520.

[20] Bhatnagar A., Kaczala F., Kriipsalu M., et al., 2012.Closing the Life Cycle of Landfills - Landfill Mining in the Baltic Sea Region for future. In: Proceedings of Linnaeus EcoTech- 2012. November 26-28, 2012, Kalmar, Sweden, pp 26-28

[21] Jones P.T., Geysen D., Tielemans Y., et al., 2013. Enhanced Landfill Mining in view of multiple resource recovery: A critical review. J. of Cleaner Production. 55. 45-55.

[22] Krook J, Baas L., 2013. Getting serious about mining the technosphere: a review of recent landfill mining and urban mining research. J. of Cleaner Production. 55. 1-9.

[23] Bosmans A., Vanderreydt I., Geysen D., Helsen L., 2013.The crucial role of Waste-toEnergy technologies in enhanced landfill mining: a technology review. J. of Cleaner Production. 55. 10-23.

[24] Burlakovs J. Kriipsalu M., Dace A., et al., 2013. Exploration and Mining former dump sites and the landfill mining perspectives in Baltic countries and Sweden: the status. In: SGEM Proceedings; Exploration and Mining: 485-492.

[25] Van Passel S.V, Dubois M., Eyckmans J., et al., 2013.The economics of enhanced landfill mining: private and societal performance drivers Journal of Cleaner Production.55. 92-102.

[26] Etzkowitz, H., Leydesdorff, L., 1995. The triple helix-university-industrygovernment relations: a laboratory for knowledge-based economic development. EASST Review. 14 (1). 14-19.

[27] Students' Campus view plan. In: http://studmisto.univ.kiev.ua/maps/mapbox.php

[28] Tubergen J., Glorius T, Waeyenbergh E .Classification of solid recovered fuels. ERFO. 2005

[29] Solid Recovered Fuels - SPECIFICATIONS AND CLASSES. Information document on EN15359

[30] Standardisation of SRF. Basic information for producers and users of SRF, public authorities and other stakeholders. ERFO 